\title{
Plasma Treatment as Green Technology for Dyeing of Textile Fabrics
}

\author{
Muhammad Naveed* \\ Department of Applied Chemistry, Government College University Faisalabad, Allama Iqbal Road 38000 - Pakistan
}

*Corresponding author: Muhammad Naveed, Department of Applied Chemistry, Government College University Faisalabad, Allama Iqbal Road 38000, Pakistan

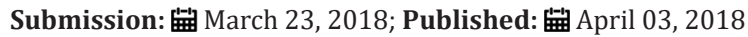

\begin{abstract}
Use of synthetic dyes for dyeing of textile fabrics are most problematic environmental concerned for textile industry owing to their toxic effect on ecosystem. Thus, sustainable novel technologies for textile dyeing are needed that utilize enhanced dye uptake and improved performance characteristics of fabric. Such technology may reduce dye concentration in waste-water effluents from textile sector and ultimately become energy efficient and cost effective. Plasma technology has proven to impart enhanced dye exhaustion, dye penetration, dyeing in shorter time with minimal of chemical auxiliaries and energy usage. The potential attributes of plasma on textile dyeing is discussed in this article..
\end{abstract}

Keywords:Plasma technology, Textile fabric; Dyeing; Applications

\section{Introduction}

Textile sector is facing an increased global competition in current decade owing to changing market conditions. The utilization of novel technical skills is thus forced for fabricating textile products for high quality performances [1]. This aspect is further accelerated to employ such technologies due to high level of hazardous chemicals in large quantities and volume of waste water textile effluents. Thus extra purification methods are needed to purify these effluents. As alternative to conventional chemical treatments, radiation has potential to tailor surface characteristics of polymeric, micro and nanostructures [2]. Among all available surface treatment methods, Plasma irradiation is observed a remarkable significance. This is a green, dry, worker friendly and ecofriendly method that can alter surface properties without major change in bulk performance of textile materials. Owing to heat sensitive nature of textile polymeric materials, non-thermal plasma is particularly suitable $[3,4]$.

\section{Plasma treatment Vs chemical modification}

Surface morphology of fiber greatly influences the choice of processing method for it. For example, a fiber having scales on its surface may exploit unwanted phenomenon like barrier of diffusion or felting. Therefore, many fiber degradation effects as well as environmental issues are concerned by using chemical treatment for modification of such fibers $[5,6]$. Thus a number of green processes have focused due to ecological and economical awareness to deal these issues.

As comparison, low yield of dyeing and more than $50 \%$ dye lost in waste water effluent, some esthetic and environmental issues can minimized by plasma treatment before, during dyeing or finishing processes. Advantageously, this technology can operate at ambient conditions with lesser of no chemical auxiliaries are needed. Thus, this technology is attributed green textile technology.

\section{Plasma treatment}

Various characteristics have developed for textiles e.g., high level of shrink resistance [7-10] wet ability [11,12]. Low temperature plasma (LTP) treatment has shown significant plasmapolymer surface interactions to tailor process and performance characteristics of dyeing wool fiber including improved dye uptake, lesser felting dispute, increased electro negativity on fiber surface [7,13-16]. In this way, penetration of dye become more penetrated in treated fiber and ultimately enhance coloration achieved. Exocutile A-layer of wool fiber is expected to under gone cytokine oxidation under exposure of sputtering results of plasma. Ultimately, partial swelling of A-layer at fiber surface occurred owing to decrease in cross-linkages and improved fiber-dye affinity. Comparatively, Acetone/argon plasma is favored in place of helium/argon plasma to improve dyeing ability of wool at room temperature towards acid dyes [14]. Furthermore, coupling enzymatic treatment along with low temperature plasma pre-treatment is significant to further increase dyeing rate of cotton and wool fabrics toward milling acid dye [17]. This performance achieved by simultaneous effect of enzymatic and plasma treatments which attack in interior and exterior of fiber respectively. Nature of plasma gas also contribute its significant effect for modifying fiber surface. For example, chrome dyeing of wool fabric is favored to use nitrogen plasma in place of oxygen plasma [18]. Thus, mordant treatment of wool fabric 
in textile processing can be substituted with plasma sputtering of which gives better performance characteristics of fabric and enhanced antibacterial properties advantageously [19]. Different schematic view of plasma sputtering setup for fabric is depicted in Figure 1. The performance of air plasma pre-treated fabrics is dependent to optimized process parameters [20,21]. Unwanted results may achieved at prolonged plasma exposure of fibe $r$ such as change in appearance of fabric and heavier weight loss.
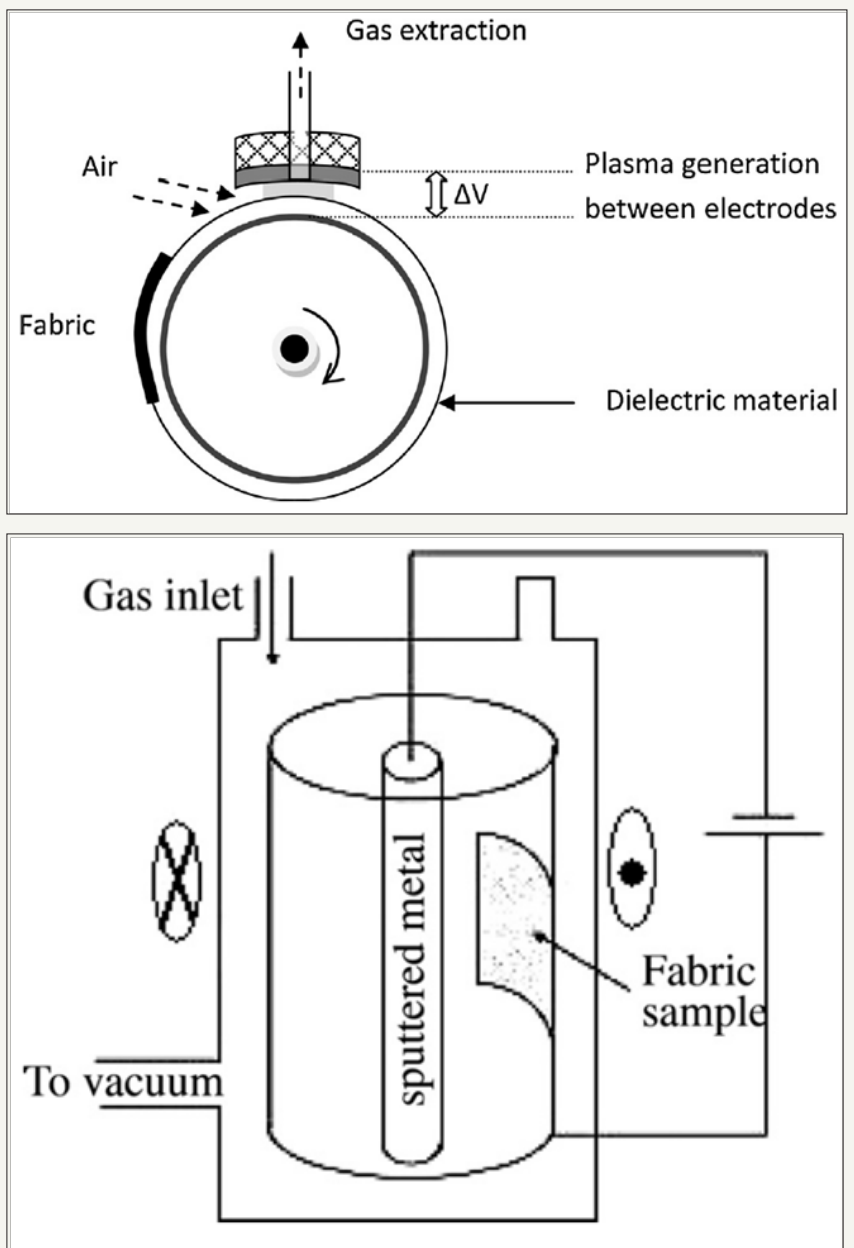

Figure 1: Schematic view of (upper) corona plasma equipment used for acrylic fabric treatment [19] (lower) the DC magnetron sputtering setup [19].

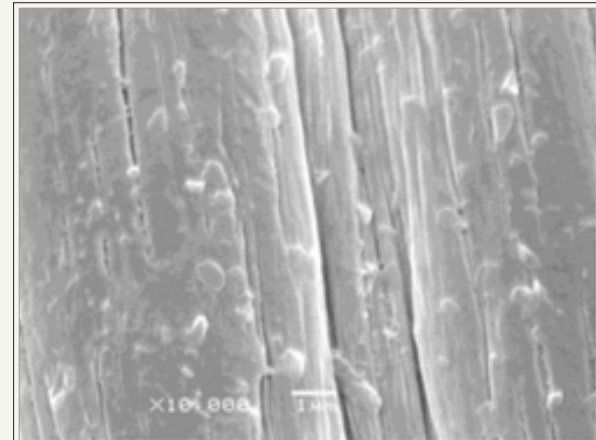

(a)

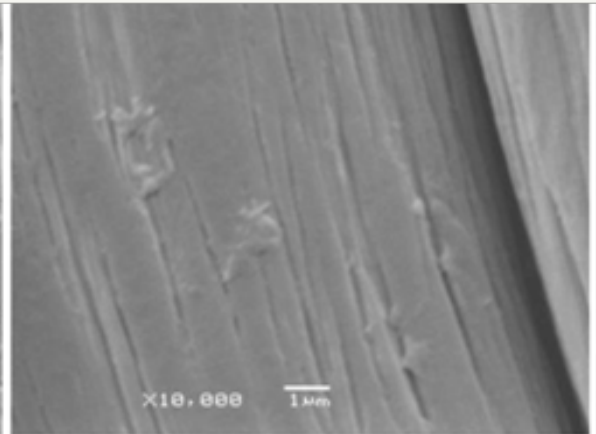

(b)

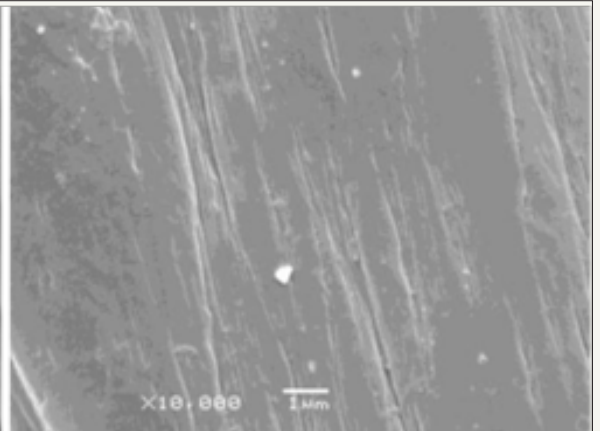

(c)

Figure 2: SEM micrographs of acrylic fiber.

(a) Untreated

(b) After corona treatment for $7 \mathrm{~s}$

(c) $28 \mathrm{~s}$. Evidence of the effect of matter removal by plasma etching observed in (b) and (c) [26] 
In place of natural fibers, plasma technology is shown extraordinary results for synthetic fibers as well. PET fabric treated by cold plasma exhibit enhanced dyeing performance owing to enhanced surface area and surface roughness induced by plasma treatment $[22,23]$. Enhanced dye exhaustion is also may be due to greater affinity and enhanced water swelling ability of PET fiber towards polar parts of dyes during dyeing process of treated PET fabric [24]. Anti-reflective coating of PET with better coloration is achieved by plasma sputter etching of organo-silicon compounds on surface of PET [25]. Corona plasma is able to remove unwanted matter substance from surface of acrylic [26] and polyamide [27] fibers as depicted in Figure $2 \& 3$.

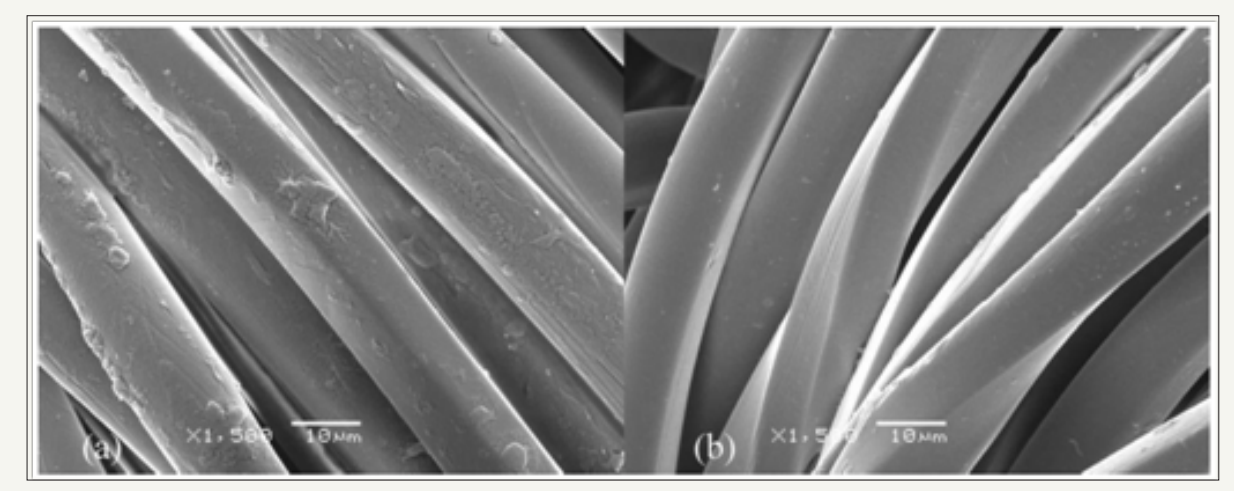

Figure 3: (a) untreated PA 66 fibers and (b) plasma-treated PA 66 fibers at 100W, 3min, 10L.min-1, and 1 Torr [27].

Furthermore, characteristic functional groups may develop on surface of fiber by plasma technology along with specific carriers for fabricating various functional and high performance applications. As a result, hydrophilicity and capillarity achieved e.g., enhanced dye diffusion in the amorphous region of PET/Viscose [28-30].
Plasma technology introduced oxidized anionic polar groups (i.e., $\mathrm{C}=\mathrm{O}, \mathrm{COOH}$ ) on fiber surface with increased hydrophilicity which enhances the interactions of fiber with dye [30,31]. The mechanism of disperse dye with treated PET fabric surface is shown in Figure 4.

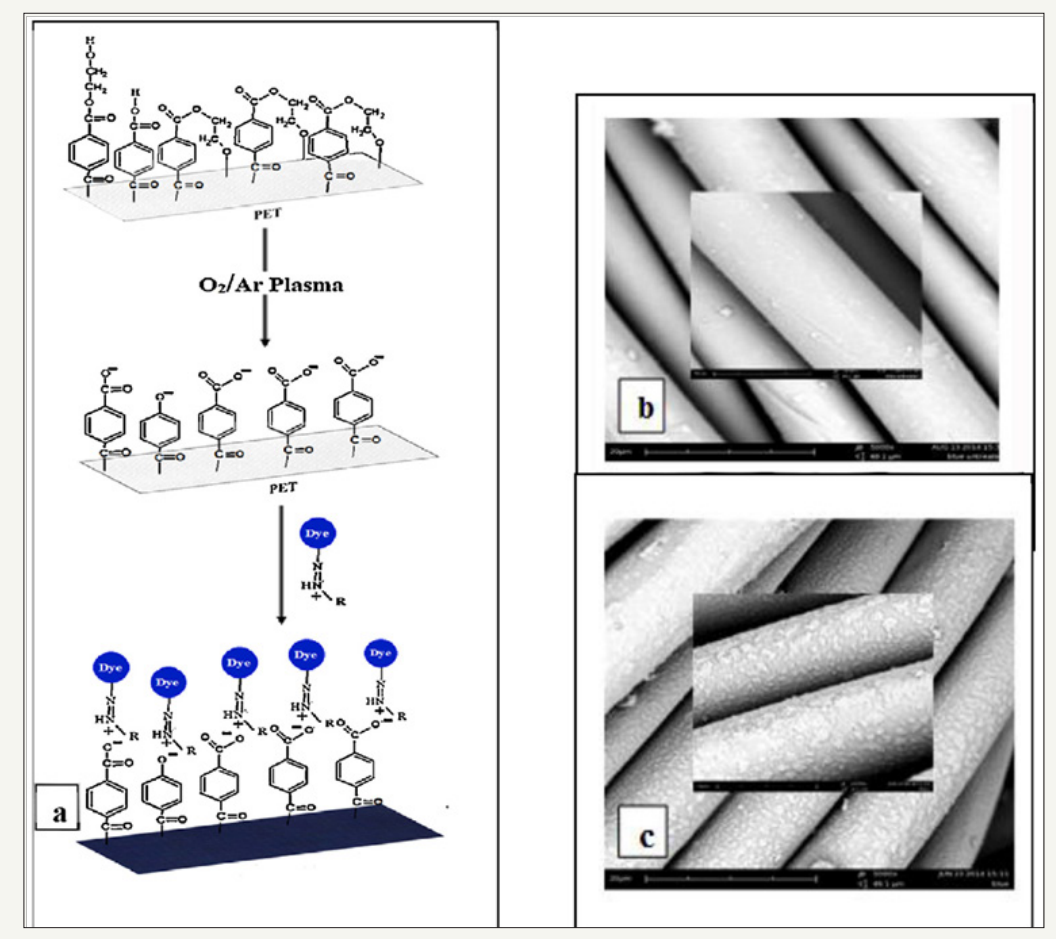

Figure 4: (a) The mechanism of disperse dye with treated PET fabric surface and SEM images (b) untreated after dyeing (c) treated after dyeing [30].

Another significant approach of utilization of Plasma technology is aim at grafting of suitable functional group on surface of fiber which also improves interaction of dye and fabric surface [32]. Introducing oxygen atoms onto surface of fabric by double barrier discharge (DBD) plasma from atmospheric oxygen is another example of this approach. Thus, plasma technology is a versatile technique having a number of advantages over conventional treatment methods. Plasma treatment has tested with a number 
of natural and synthetic fabrics such as silk [33,34], wool [3541], cotton [16,42-51], polyethylene [52], polypropylene [53-55], polyester [22,56-60], polyamide [61-64], ramie [65] and viscose fibers [66].

\section{Conclusion}

This article is an attempt to exploit and summarize potential aspects of plasma technology for textile dyeing to be employed in textile sector. Plasma treatment is a dry and clean technique operates at ambient temperature which is able to improve coloration and to develop characteristic functionalities on surface of textile fabric without altering the performance of bulk fiber. Furthermore, plasma treatment can couple with other natural treatment methods which further improve the performance of treated fabric. This results insignificant reduction of toxic chemicals and auxiliaries in effluent load which diminish energy usage and cost and environmental impact.

\section{References}

1. Gorjanc M, Gorenšek M, Jovančić P, Mozetič M (2013) Multifunctional textiles modification by plasma, dyeing and nanoparticles. Eco Friendly Textile Dyeing and Finishing.

2. Saif MJ, Naveed M, Asif HM, Akhtar R (2018) Irradiation applications for polymer nano-composites: A state-of-the-art review. Journal of Industrial and Engineering Chemistry 60: 218-236.

3. Borcia G, Dumitrascu N, Popa G (2005) Influence of helium-dielectric barrier discharge treatments on the adhesion properties of polyamide- 6 surfaces. Surface and Coatings Technology 197(2-3): 316-321.

4. Morent R, De Geyter N, Verschuren J, De Clerck K, Kiekens P, et al. (2008) Non-thermal plasma treatment of textiles. Surface Coatings Technology 202(14): 3427-3449.

5. Roberts GAF and Wood FA (2001) A study of the influence of structure on the effectiveness of chitosan as an anti-felting treatment for wool. J Biotechnol 89(2-3): 297-304.

6. Negri AP, Cornell HJ, Rivett DE (1993) The modification of the surface diffusion barrier of wool. Journal of the Society of Dyers and Colourists 109(9): 296-301.

7. Tokino S, Wakida T, Uchiyama H, Lee L (1993) Laundering shrinkage of wool fabric treated with low-temperature plasmas under atmospheric pressure. Journal of the Society of Dyers and Colourists 109(10): 334335.

8. Jovancic P, Jocic D, Molina R, Julia MR, Erra P (2003) The combined lowtemperature plasma/enzyme wool shrink-resist treatment. AATCC Rev 3: $25-28$.

9. Erra P, Molina R, Jocic D, Julia MR, Cuesta A, et al. (1999) Shrinkage properties of wool treated with low temperature plasma and chitosan biopolymer. Textile Research Journal 69(11): 811-815.

10. Sun D, Stylios GK (2006) Fabric surface properties affected by low temperature plasma treatment. Journal of Materials Processing Technology 173(2): 172-177.

11. Wróbel A, Kryszewski M, Rakowski W, Okoniewski M, Kubacki Z (1978) Effect of plasma treatment on surface structure and properties of polyester fabric. Polymer 19(8): 908-912.

12. Tsai PP, Wadsworth LC, Roth JR (1997) Surface modification of fabrics using a one-atmosphere glow discharge plasma to improve fabric wettability. Textile Research Journal 67(5): 359-369.
13. Wakida T, Lee M, Sato Y, Ogasawara S, Ge Y, et al. (1996) Dyeing properties of oxygen low-temperature plasma-treated wool and nylon 6 fibres with acid and basic dyes, Coloration Technology 112(9): 233-236.

14. Wakida T, Tokino S, Niu S, Lee M, Uchiyama H, et al. (1993) Dyeing properties of wool treated with low-temperature plasma under atmospheric pressure. Textile Research Journal 63(8): 438-442.

15. Lee M, Wakida T (1992) Dyeing property of plasma-treated wool with direct dyes. Sen'i Gakkaishi 48(12): 699-703.

16. Sun D, Stylios GK (2004) Effect of low temperature plasma treatment on the scouring and dyeing of natural fabrics. Textile Research Journal 74(9): 751-756.

17. Yoon NS, Jin LY, Tahara M, Takagishi T (1996) Mechanical and dyeing properties of wool and cotton fabrics treated with low temperature plasma and enzymes. Textile Research Journal 66(5): 329-336.

18. Kan C, Chan K, Yuen CW, Miao M (1998) The effect of low-temperature plasma on the chrome dyeing of wool fibre. Journal of Materials Processing Technology 82(1): 122-126.

19. Ghoranneviss M, Shahidi S, Anvari A, Motaghi Z, Wiener J, et al. (2011) Influence of plasma sputtering treatment on natural dyeing and antibacterial activity of wool fabrics. Progress in Organic Coatings 70(4): 388-393.

20.Zhang LS, Liu HL, Yu WD (2015) Effect of air plasma treatment on the dyeing of tencel fabric with C.I. reactive black 5. Applied Surface Science 328: 501-508.

21. Dayioglu H, Kut D, Merdan N, Canbolat S (2015) The effect of dyeing properties of fixing agent and plasma treatment on silk fabric dyed with natural dye extract obtained from sambucus ebulus L Plant. Procedia Social Behavioral Sciences 195: 1609-1617.

22. Raffaele AA, Elena S, Ruggero B, Francesco O (2006) Cold plasma-induced modification of the dyeing properties of poly(ethylene terephthalate) fibers. Applied Surface Sciences 252(6): 2265-2275.

23. Ferrero F, Tonin C, Peila R, Pollone FR (2004) Improving the dyeability of synthetic fabrics with basic dyes using in situ plasma polymerisation of acrylic acid. Coloration Technology 120(1): 30-34.

24. Jie RC, Xue YW, Tomiji W (1999) Wettability of poly (ethylene terephthalate) film treated with low-temperature plasma and their surface analysis by ESCA. Journal of Applied Polymer Science 72(10): 1327-1333.

25. Lee HR, Kim Dj, Lee KH (2001) Anti-reflective coating for the deep coloring of PET fabrics using an atmospheric pressure plasma technique. Surface and Coatings Technology 142: 468-473.

26. Labay C, Canal C, Rodríguez C, Caballero C, Canal JM (2013) Plasma surface functionalization and dyeing kinetics of Pan-Pmma copolymers. Applied Surface Science 283: 269-275.

27. Labay C, Canal JM, Canal C (2012) Relevance of surface modification of polyamide 6.6 fibers by air plasma treatment on the release of caffeine. Plasma Process and Polymers 9(2): 165-173.

28. Canbolat S, Kilinc M, Kut D (2015) The investigation of the effects of plasma treatment on the dyeing properties of polyester/viscose nonwoven fabrics. Procedia Social and Behavioral Sciences 195: 21432151.

29. Agnhage T, Perwuelz A, Behary N (2016) Eco-innovative coloration and surface modification of woven polyester fabric using bio-based materials and plasma technology. Industrial Crops and Products (86): 334-341.

30. Elabid AEA, Zhang J, Shi J, Guo Y, Ding K, et al. (2016) Improving the low temperature dyeability of polyethylene terephthalate fabric with dispersive dyes by atmospheric pressure plasma discharge. Applied Surface Science 375: 26-34. 
31. Lai J, Bob S, Jianming X, Sha Y, Weijiang Z, et al. (2006) Study on hydrophilicity of polymer surfaces improved by plasma treatment Applied Surface Science 252(10): 3375-3379.

32. Salem T, Pleul D, Nitschke M, Müller M, Simon F (2013) Different plasma-based strategies to improve the interaction of anionic dyes with polyester fabrics surface. Applied Surface Science 264: 286-296.

33. Iriyama Y, Mochizuki T, Watanabe M, Utada M (2002) Plasma treatment of silk fabrics for better dyeability. Journal of Photopolymer Science and Technology 15(2): 299-306.

34. Shahidi S (2015) Plasma sputtering as a novel method for improving fastness and antibacterial properties of dyed cotton fabrics. The Journal of The Textile Institute 106(2): 162-172.

35. Sadeghi KM, Tayebi HA (2017) Eco-friendly reactive dyeing of modified silk fabrics using corona discharge and chitosan pre-treatment. The Journal of The Textile Institute 108(7): 1164-1172.

36. Cai Z, Qiu Y (2008) Dyeing properties of wool fabrics treated with atmospheric pressure plasmas. Journal of Applied Polymer Science 109(2): 1257-1261.

37. El Zawahry MM, Ibrahim NA, Eid MA (2006) The impact of nitrogen plasma treatment upon the physical-chemical and dyeing properties of wool fabric. Polymer Plastics Technology and Engineering 45(10): 11231132

38. Jocic D, Pilar Erra, Maria Rosa Julià (2005) Effect of low-temperature plasma and chitosan treatment on wool dyeing with acid red 27. Journal of Applied Polymer Science 97(6): 2204-2214.

39. Molakarimi M, Khajeh MM, Haji A (2016) Effect of plasma treatment and grafting of $\beta$-cyclodextrin on color properties of wool fabric dyed with Shrimp shell extract. The Journal of The Textile Institute 107(10): 13141321.

40. Gaidau C, Niculescu MD, Surdu L, Dinca L, Barbu I (2017) Improved properties of wool on sheepskins by low pressure plasma treatment. Industria Textila 68(3): 193

41. Hala A, Karaca GY, Eren E, Oksuz L, Bozduman F, et al. (2017) Surface properties of radio frequency plasma treated wool and denim fabrics. Research Journal of Textile and Apparel 21(2): 101-110.

42. Ratnapandian S, Wang L, Fergusson SM, Naebe M (2011) Effect of atmospheric plasma treatment on pad-dyeing of natural dyes on wool. J Fiber Bioeng Informatics 4(3): 267-276.

43. Karahan HA, Ozdogan E, Demir A, Ayhan H, Seventekin N, (2008) Effects of atmospheric plasma treatment on the dyeability of cotton fabrics by acid dyes. Coloration Technology 124(2): 106-110.

44. Nourbakhsh S, Valipour P, Yazdanshenas ME, Ebadi A G (2008) Dyeability improvement of cationized corona discharge treated cotton fabric. Asian J Chem 20(5): 3543-3548.

45. Shahidi S, Ghoranneviss M, Ilali R, Karami M, Miladi M (2016) Dyeing properties of the atmospheric pressure plasma-treated polypropylene fabric subjected to butane tetra carboxylic acid. The Journal of The Textile Institute 107(5): 636-644.

46. Helmy HM, Hauser P, Shafei AEl (2017) Influence of atmospheric plasma-induced graft polymerization of DADMAC into cotton on dyeing with acid dyes. The Journal of The Textile Institute 108(11): 1871-1878.

47. Ghoranneviss M, Shahidi S (2017) Color intensity and wash fastness properties of dyed cotton fabric after plasma treatment. The Journal of The Textile Institute 108(3): 445-448.

48. Gorjanc M, Savić A, Topalić-Trivunović L, Mozetič M, Vesel A, Grujić D, (2016) Dyeing of plasma treated cotton and bamboo rayon with Fallopia japonica extract. Cellulose 23(3): 2221-2228.
49. Ibrahim NA, Eid BM, Abdel-Aziz MS (2017) Effect of plasma superficial treatments on antibacterial functionalization and coloration of cellulosic fabrics. Applied Surface Science 392: 1126-1133.

50. Cornelius C, McCord M, Bourham M, Hauser P (2017) Desizing of starch sized cotton fabrics with atmospheric pressure plasma. Cellulose 24(12): 5685-5695.

51. Ražić SE, Čunko R, Bautista L, Bukošek V (2017) Plasma effect on the chemical structure of cellulose fabric for modification of some functional properties. Procedia Engineering 200: 333-340.

52. Ren Y, Ding Z, Wang C, Zang C, Zhang Y, Xu L (2017) Influence of DBD plasma pretreatment on the deposition of chitosan onto UHMWPE fiber surfaces for improvement of adhesion and dyeing properties. Applied Surface Science 396: 1571-1579.

53. Ibrahim NA, Hashem MM, Eid MA, Refai R, El-Hossamy M, Eid BM, et al. (2008) Eco-friendly plasma treatment of linen-containing fabrics. J Text Inst 101(12): 1035-1049.

54. Yaman N, Özdogan E, Seventekin N, Ayhan H (2009) Plasma treatment of polypropylene fabric for improved dyeability with soluble textile dyestuff. Appl Surf Sci 255(15): 6764-6770.

55. Souto AP, Oliveira FR, Carneiro N (2011) Polyamide 6.6 modified by DBD plasma treatment for anionic dyeing processes, in Textile Dyeing.

56. Shahidi S, Ghoranneviss M, Moazzenchi B, Rashidi A, Dorranian D (2007) Effect of using cold plasma on dyeing properties of polypropylene fabrics. Fibers Polym 8(1): 123-129.

57. Mirjalili M, Karimi L (2013) The impact of nitrogen low temperature plasma treatment upon the physical-chemical properties of polyester fabric. Journal of The Textile Institute 104(1): 98-107.

58. Wang CC, Lin LH, Chen CW, Lo YC (2017) Surface Modification of Poly (lactic acid) Fabrics with Plasma Pretreatment and Chitosan/Siloxane Polyesters Coating for Color Strength Improvement. Polymers 9(8): 371.

59. Zhang C, Zhao M, Wang L, Qu L, Men Y (2017) Surface modification of polyester fabrics by atmospheric-pressure air/He plasma for color strength and adhesion enhancement. Applied Surface Science 400: 304311.

60. Belhaj Khalifa I, Ladhari N, Nemeshwaree B, Campagne C (2017) Crosslinking of Sericin on air atmospheric plasma treated polyester fabric. The Journal of The Textile Institute 108(5): 840-845.

61. Hossain MM, Müssig J, Herrmann AS, Hegemann D, (2009) Ammonia/ acetylene plasma deposition: An alternative approach to the dyeing of poly(ethylene terephthalate) fabrics at low temperatures. J Appl Polym Sci 111(5): 2545-2552.

62. Yip J, Chan K, Sin KM, Lau KS (2002) Study of physico-chemical surface treatments on dyeing properties of polyamides. Part 1: Effect of tetrafluoromethane low temperature plasma. Color Technol 118(1): 2630.

63. Oliveira FR, Souto AP, Carneiro N, Nascimento JHO (2010) Surface Modification on Polyamide 6.6 with Double Barrier Discharge (DBD) Plasma to Optimise Dyeing Process by Direct Dyes. Mater Sci Forum (636): 846-852.

64. Oliveira FR, Zille A, Souto AP (2014) Dyeing mechanism and optimization of polyamide 6, 6 functionalized with double barrier discharge (DBD) plasma in air. Applied Surface Science 293: 177-186.

65. Liu X, Cheng L (2017) Influence of plasma treatment on properties of ramie fiber and the reinforced composites. Journal of Adhesion Science and Technology 31(15): 1723-1734.

66. Karthikeyan N, Vijayalakshmi KA, Vignesh K (2016) Effect of glow discharge oxygen plasma treated surface and antimicrobial properties of viscose fabric. Materials Technology 31(3): 166-175. 
Creative Commons Attribution 4.0 International License

For possible submissions Click Here

Submit Article

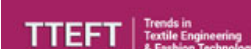
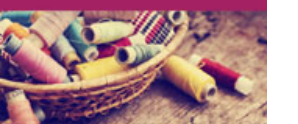

.

(2)
Trends in Textile Engineering \& Fashion Technology

Benefits of Publishing with us

- High-level peer review and editorial services

- Freely accessible online immediately upon publication

- Authors retain the copyright to their work

- Licensing it under a Creative Commons license

- Visibility through different online platforms 